\title{
Forecasting University Enrollment: An Historical Case Of A College Of Business In Northeast United States Of America
}

Ilan Alon, (E-mail: ilan.alon@rollins.edu), Rollins College

\begin{abstract}
This article attempts to provide a framework for predicting enrollments accurately and in a timely fashion. Several projection models are developed for predicting full-time, first-time enrollment. A case of a regional University in NJ with a large college of business - which we will call COB (standing for College of Business, its primary focus) for purposes of anynomity -- is used to provide an historical example. Information on competitive analysis is also provided.
\end{abstract}

\section{BACKGROUND ON THE STUDY}

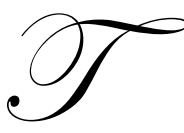

he objective of the report's study were (1) To project enrollments to the year 2000, in order to enhance financial budgeting, as well as strategic and research planning; (2) To determine and analyze external factors responsible for the decline in enrollment; (3) To provide competitive analysis.

To achieve these objectives, analyses of the institution and its environments are presented. Since 70 to 80 percent of COB enrollments are instate residents, and more than $95 \%$ of the first-time, full-time (FT/FT) students are under 21 years of age, the focal unit of analysis for this report has been NJ high school graduates. Table 1 shows how ther percentages over the years of $\mathrm{NJ}$ enrollment out of total enrollment in $\mathrm{COB}$, showing a stable but decreasing trend between 1986 to 1992.

Table 1: The Relationship Between NJ Enrollment and Total Enrollment

\begin{tabular}{cccc}
\hline YEAR & COB TOTAL ENRL & COB NJ ENRL & \% NJ ENRL \\
1986 & 793 & 629 & 0.793190 \\
1987 & 806 & 615 & 0.763027 \\
1988 & 922 & 703 & 0.762473 \\
1989 & 700 & 545 & 0.778571 \\
1990 & 639 & 480 & 0.751174 \\
1991 & 485 & 333 & 0.686598 \\
1992 & 469 & 300 & 0.639659 \\
\hline
\end{tabular}

Analyses herein are provided for FT/FT student headcounts, excluding FT/FT freshmen in the two year programs-such as the dental hygiene program, allied health program, and the two year college for the fall semesters 1986-1993. 
Fall semesters were used since they represent the semesters in which the bulk of FT/FT freshmen are enrolled. (Krohn, 1994). This is confirmed by national trends indicating that $92.5 \%$ of college freshmen continue right from high school, without a pause (Case, 1994).

\section{INSTITUTIONAL BACKGROUND}

Since 1942, when COB was founded, until the early 1980's, the University had enjoyed constant growth and prosperity. Due to regional economic growth, the baby boom generation and a "favorable" political climate, enrollment at COB had risen steadily. As a result, management at $\mathrm{COB}$ invested heavily in physical facilities, with little regard to long-term trends, growing from a single campus to a three campus configuration, with two overseas campuses in the Virgin Islands and England.

The baby boom generation aged and the University did not change its marketing orientation. Catering to the traditional college age crowd, 18 to 21 (see exhibit 1), the University had felt the pinch when the number of high school graduates declined precipitously in the 1980's. Between 1980 and 1990, high school graduation rates declined by more than $20 \%$ in NJ. During the same period, competition intensified for this market segment from the military, employers, and state colleges, which completed their transition from teacher's colleges to comprehensive institutions and could afford to charge much lower tuition.

Taking a reactive approach, $\mathrm{COB}$ responded to the trends by attempting to cut costs. The University consolidated and eliminated academic programs, and centralized administrative functions. However, these actions were abrupt and ineffective. The University was forced to raise tuition and enrollments declined faster than the number of high school graduates; market share was lost. From 1988 to 1992, COB lost market share. For the first time in 1993, due to a strong marketing campaign, the University regained some market share. Table 2 shows COB's declining NJ high school graduates' market share between 1986 and 1993.

Table 2: COB's Market Share of NJ High School Graduates

\begin{tabular}{ccccc}
\hline YEAR & NJ HS & COB ENRL & MKI SHAR & TUIT/CRT \\
1986 & 78781 & 793 & 0.0079842 & 203 \\
1987 & 79367 & 806 & 0.0077488 & 224 \\
1988 & 80863 & 922 & 0.0086937 & 227 \\
1989 & 76263 & 922 & 0.0071463 & 248 \\
1990 & 69824 & 639 & 0.0068744 & 283 \\
1991 & 67003 & 485 & 0.0049699 & 308 \\
1992 & 66669 & 455 & 0.0051496 & 347 \\
\hline
\end{tabular}

COB's failure to project enrollments accurately, created budgetary distortions, excess costs over revenue and misdirection in strategic planning, leading to the Strategic Planning Commission's (1991) comment that the University lacked clarity about its overall direction. Institutional survival depends in large part on adherence to and execution of a viable vision, and the University was lacking it.

For the period 1989-1993, undergraduate consumption credits in COB decreased 15\%, while the current unrestricted fund deficit increased 45\%, resulting in a nationally publicized Standard and Poors rating of "BBB." By 1993 , COB's current unrestricted fund deficit grew to $\$ 37.8$ million. If the trends have continued, the University's ability to operate as a going concern will be diminished. 


\section{SITUATION ANALYSIS}

The 1980s were turbulent times for private and public universities because of a significant decline in enrollment. Regional universities in New Jersey were particularly hit because:

1. Demographic changes and the number of high school graduates in NJ

2. NJ schools of higher education and COB's positioning

3. Interest in business and related fields

COB decline in enrollments outpaced the decline in the number of high school graduates between 1988 and 1992. Fortunately, in 1993, for the first time since 1988, COB regained some market share, up 14\% from its 1992 level, despite unfavorable news and a loss of a number of international students due to visa denials by their countries. Nonetheless, a lack of differentiation, coupled with increased tuition rates, makes it difficult for the University to effectively increase its number of students vis-à-vis the number of high school graduates, all other factors held constant.

A strong correlation was discovered between $\mathrm{COB}$ enrollment and high school graduates in NJ. After bottoming out in 1993, the number of high school graduates is expected to grow modestly, a cumulative total of $10 \%$ by the year 2000. Furthermore, according to the U.S. Department of Education, enrollments at private institutions will grow at a rate slower than their public counterparts

Changes in New Jersey's higher education environment had a profound effect on private institutions. In light of intensifying competition, these institutions have been forced to carve out market niches. Institutions which did not raise their perceived quality vis-a-vis tuition, i.e. value, suffered the consequences including financial deterioration; and in the case of Upsala College possible loss of accreditation, and subsequent bankruptcy.

\section{ENROLLEMENT TRENDS}

\section{National Trends}

According to the United States Department of Education, higher education enrollment increased from 11.6 million to 12.5 million between 1979 and 1993. In 1984 and 1985, higher education enrollment dropped from 12.5 million to 12.2 million. Then, it increased to 14.6 million by 1992. Overall, national enrollment increased 16 percent from 1986 to 1992. However, these increases are the result of the rise in adult education since the number of high school graduates had declined for the same period.

After reaching a peak in 1979, the number of students graduating from the nation's high schools began to decline, dropping precipitously in the 1980's. After bottoming out in 1994, the size of the nation's high school graduating class will begin to rise steadily. By the year 2009, the majority of the states will have recovered from the declines of the 1980s and 1990s, but will still fall below 1979 levels (WICHE, 1993). Enrollments at private institutions will increase modestly from 2.4 minion to 2.5 million between 1993 and 2000, a total increase of a mere $4 \%$.

\section{Regional Trends}

In 10 Northeast states, including COB's main feeder states ( see exhibit 5)Maryland, Massachusetts, New York, and Pennsylvania-graduates are expected to increase beginning in the early 1990s, peaking between 2007 and 2009 (WICHE, 1993). 


\section{New Jersey Trends}

New Jersey trends are perhaps the most important to COB since COB is a local institution. New Jersey population growth was slower in the state than in the nation as a whole during the 1980s. The four counties that COB rely on most for its FT/FT freshmen-Bergen (14.6\%), Essex (14.5\%), Hudson (8.0\%), and Union (4.6\%) (see exhibit 6)-lost population during the 1980s. Essex County experienced the greatest loss $(-73,098$ persons or $-8.6 \%)$, followed by Bergen (-20,005 persons or $-2.4 \%)$, Union (-10,275 persons or $-2.0 \%)$, and Hudson $(-3,873$ or $-0.7 \%)$ (Hughes \& Hughes, 1990).

It is projected that the state's population will continue to grow in the 21 st century at a rate lower than the nation's, growing from 7,730,188 in 1990 to $8,344,500$ in the year 2005 to $9,426,700$ by the year 2030. Both the $7.9 \%$ growth between 1990 and 2005 and the $13 \%$ change from 2005 to 2030 can be translated into a 0.5 percent annual growth rate, compared with .84 percent national growth rate (New Jersey Department of Labor). By the year 2000, the baby boom generation will taper. New Jersey population growth will lag behind that of the 1980s, an inevitability reinforced by the expectation of modest state economic fortunes. The 45-54 year old population will dominate the age structure chart (Hughes et al., 1990). (For New Jersey statistics and projections see exhibit 4).

\section{METHODOLOGIES}

"A forecast done simply to satisfy curiosity is of no value" (Copulski, 1970). COB used the the enrollment forecasts to adjust budgeting and strategic planning. Universities should prepare realistic plans of the future which will provide a reasonable road map for institutional change, expansionary or contractionary.

A projection is the measurement of a future condition that would exist if the assumptions and procedures of the method proved to be empirically valid in the future. Given the method and assumptions, a projection is always correct if the operations of the projection method are carried out without error (NJ Dept. of Labor, 1993).

The projections presented herein are baseline, assuming trended changes in historical conditions will continue to the future. As such, plausibility of historically based assumptions declines with increasing departure from the base year. As a rough rule of thumb, it might be expected that about two-thirds of the time, a 5-year projection will be within plus or minus 10 percent of actual results (Copulsky, 1970).

It is assumed that no significant change within the economic, political/ legal, social, competitive or international environments will occur until the year 2000. And no significant internal changes in tuition, academic admission requirements, and curricular configuration etc. will take place for the projected time frame (Lins, 1964).

A forecast is a projection that is also a judgmental statement concerning the expected measurement of future condition; it is an educated guess. Copulsky (1970) claims that a company experiencing declining sales should forecast pessimistically, and when a firm experiences growth it should forecast optimistically. Given COB enrollment record in recent years, it would seem logical to predict conservatively.

\section{RESULTS}

\section{Regression Analysis}

Correlation analysis is one of the most useful analytical tools in evaluating historical data. It is reliable and rapid in estimating the "normal" trend thus passing a marginal cost/ benefit analysis (Lee, 1993). However. independent judgments should not be abandoned. The correlation equation is a practical device whose value in forecasting can only be determined by its success in actual use. It is designed to make use only of demand factors that account for most of the variation in demand, assuming that the net result of the many other minor demand forces interact in a random way (Copulsky, 1970). 
In attempting to determine the association between enrollment (depended variable) and one or more independent factors, three concomitant relationships were discovered-from which five regression analyses were produced. All models pass Libren and Korler evaluation criteria for theoretical, descriptive, and normative soundness (1985). With the passage of time, the models should be tested, evaluated, and refined accordingly. The regression show that the number of high school graduates is the single most important variable in predicting enrollement and, as such, the projections of these numbers can be used to predict the number of enrolled students.

For the projection purpose, only the enrollment-NJ high school graduate model providing the highest coefficient of determination-was used because it is the only equation for which the future, independent variable is known. Future numbers of high school graduates in NJ were derived by divising projections from three different "reliable" sources-NJ Department of Education, US Department of Education, and the combined study provided by Western Interstate Commissions for Higher Education (WICHE) and the College Board. Variations in projection are due to differences in assumptions, e.g., cohort-survival rates, migration, economic condition, mortality rates, etc. Table 3 shows the regression analysis results.

Table 3: Regression Analysis Results Looking into the Future

\begin{tabular}{rrrcccc}
\hline Yr. & NJ Dept. & US Dept & Commission & AY_9_- & Project 95\% & Confidence Interval \\
1994 & 66,868 & 61,340 & 67,212 & $65,140.0$ & 449.210 & \pm 199.689 \\
1995 & 68,895 & 62,900 & 70,619 & $67,471.3$ & $510-990$ & \pm 114.869 \\
1996 & 69,637 & 62,860 & 72,018 & $68,171.7$ & 529.549 & \pm 113.721 \\
1997 & 71,469 & 64,980 & 74,680 & $70,376.3$ & 587.973 & \pm 111.081 \\
1998 & 72,321 & 65,590 & 72,983 & $70,298.0$ & 585.897 & \pm 111.149 \\
1999 & 73,886 & 66,210 & 71,634 & $70,576.7$ & 593.282 & \pm 110.917 \\
2000 & 75,533 & 67,510 & 73,081 & $72,048.0$ & 632.272 & \pm 110.111 \\
\hline
\end{tabular}

When using regression analysis, great caution should be taken in interpreting the results._Regression analysis assumes functionality, and in this case linear functionality. Since enrollment numbers are rebounding and direct correlation exists between them and market share, the model assumes that $\mathrm{COB}$ will regain its previous position. This assumption may be erroneous and unrealistic. Also other factors are assumed to be held constant (e.g., tuition, trends, acceptance standards).

In addition to correlation analyses, a normative model was developed based on ratio/market share analysis. Although this model is least backed by quantitative reasoning /proof, it may provide the most accurate results. The ratio method determines the most current relation between FT/FT freshmen enrolled in COB and the population from which they come, and applies it uniformly to the future. Table 4 shows the market share forecast using the latest year of market share information at the time of the analysis. Table 5 shows the percentage of business students enrolled in COB. 
Table 4: Market Share Forecast

\begin{tabular}{cccc} 
Year & Average NJ HS Grads & $\mathbf{1 9 9 3}$ Market Share & Predict \\
& & & \\
1994 & 65,140 & .0051496 & 335 \\
1995 & 67,471 & .0051496 & 347 \\
1996 & 68,172 & .0051496 & 351 \\
1997 & 70,376 & .0051496 & 362 \\
1998 & 70,298 & .0051496 & 362 \\
1999 & 70,577 & .0051496 & 363 \\
2000 & 72,048 & .0051496 & 371 \\
\hline
\end{tabular}

Table 5: Business Education as a Percentage of Total Enrollment in COB

\begin{tabular}{lcccccccc}
\hline & \multicolumn{7}{c}{ Full-Time Senior Student Distribution By College } \\
& 1986 & 1987 & 1988 & 1999 & 1990 & 1991 & 1992 & 1993 \\
Business & $52 \%$ & $49 \%$ & $49 \%$ & $46 \%$ & $50 \%$ & $52 \%$ & $48 \%$ & $49 \%$ \\
Other Colleges & $48 \%$ & $51 \%$ & $51 \%$ & $54 \%$ & $50 \%$ & $48 \%$ & $52 \%$ & $51 \%$ \\
\hline
\end{tabular}

The above information demonstrates that $\mathrm{COB}$ has a very strong business education orientation, partly explaining the precipitous decline in enrollment as the reader will soon find out.

The all time high for interest in business was $27.3 \%$ in 1987 (Cage, 1994). Since then, surveys indicate that the number of undergraduates planning for major in business has dropped by a third, and by 40 percent for FT/FT female undergraduates (Deutsch, 1993). For six years in a row, interest in business majors continuously declined, dropping to $16.1 \%$ in 1993 from 16.3\% in 1992 (Cage, 1994). Decline in interest for COB business majors was much more pronounced, amounting to 10.5\% from 1992 to 1993 (College Board, 1993). The 10 schools with the largest undergraduate business enrollments, however, all posted declines during 1993 academic year; three out of the 10-Arizona State and Michigan State-have experienced declines of at least 25\% since 1990 (Tooley, 1994). COB posted declines of $29 \%$ for the same time period.

Four years after the all-time high for interest in business education, the number of bachelors degrees in business declined in 1991 for the first time in 30 years. Why has interest in business education declined so fast since 1987? It is not exactly clear, but some experts believe that it is a result of cultural change. For many students the definition of "success" has changed form contribution to oneself to contribution to society (Deutsch, 1993), explaining the sudden surge in demand for allied health education. Director of projects and services of the AACSB said "Today's students view contributing to society and improving lives of other people as more important than high financial rewards" (1993). Tooley states that as economic growth contracts, so do career opportunities for business majors (1994). Accordingly, it is no longer a belief that a business degree is a key to success (Deutsch, 1993). Clearly, this is a cyclical matter.

At the time, many students, as well as employers, believed that liberal arts education is a viable alternative to business educations (Tooley, 1994). The AACSB and business schools have taken several measures to stimulate demand. The AACSB began mandating that at least 50 percent of business major's classes be in non-business courses, up from 40 percent standard previously. Business schools, including COB, start offering combination programs, such as dual majors and accelerated undergraduate /graduate degree combinations. 
In summary, competition and declining interest in business changed the market from a seller's market to a buyer's market (Tooley, 1994). Higher education institutions must realize they have to adapt to the changing environments, and sensitize their marketing, as well as curriculum configuration, to student's and employer's needs.

\section{COMPETITIVE ANALYSIS}

In a special report for the Board of Trustees, "Managing Enrollment During A Time of Transition" (1993), a number of interesting observations were made concerning COB's competitive stance. "COB's inquiry numbers are more than three times the national average of other private, four-year institutions. The University's applicant yield for four-year students, however, is $54 \%$ below the average, and the yield of accepted candidates to enrolled is $26 \%$ below the average for four-year students." The report further indicated that "a low inquiry-to-application rate should prompt $[\mathrm{COB}]$ to further investigate its competition."

A customized list was developed, ranking the competition in order of the ratio of the number of SAT senders overlap and total SAT senders for each school. The more SAT senders a school has, the higher the probability of overlap with any institution, including COB. Therefore, overlap was ranked in relation to total SAT senders for each school. The results provide a frame of comparison of COB's image in the minds of prospective students. Three more academic elements - academic reputation, acceptance rate, and Carnegie Classification - were juxtaposed to give the analysis more scope. The Carnegie Classification is frequently used by campus officials to analyze their institution's academic orientation among the nation's colleges and universities. (Evangelauf, 1994) (see exhibit 1). The University was also advised to check what was important to students in choosing a college to attend. At the time, the Chronicle for Higher Education published an article listing the most important factors, shown in table 6.

Table 6: Critical Access Factors in Recruiting FT/FT Freshmen

\begin{tabular}{lr}
\hline Good Academic Reputation & $51.6 \%$ \\
Graduates Get Good Jobs & $43.4 \%$ \\
Size of College & $37.70 / \mathrm{a}$ \\
Low Tuition & $32.0 \%$ \\
Offered Financial Assistance & $31.6 \%$ \\
Good Rep for Social Activities & $25.6 \%$ \\
Graduates go to top graduate schools & $24.6 \%$ \\
Graduates Offered Special Education Programs & $23.7 \%$ \\
Wanted to Live Near Home & $20.0 \%$ \\
Friend's suggestion & $10.2 \%$ \\
Relative's wishes & $9.8 \%$ \\
Advise of Guidance Counselor & $9.4 \%$ \\
Recruited by Athletics & $5.8 \%$ \\
Religious Affiliation of College & $5.2 \%$ \\
Teachers Advice & $4.8 \%$ \\
Recruited by College & $4.4 \%$ \\
Not Accepted Anywhere Else & $2.9 \%$ \\
\hline
\end{tabular}

Reasons Noted as Very Important in Selecting College Attended (Chronicle of Higher Education 1994) 


\section{CONCLUSIONS}

Universities are competitive businesses that need to think to appeal to their customers and manage their enrollment appropriately. The current paper suggest a number of models that universities can use to model their enrollments. Proper enrollement forecasting is critical for planning, control, and resource allocation.

Competitive analysis can help universities identify the areas in which they are best suited to offer a differential advantage. Universities are advised to use limited resources in a way most suitable for attracting students in their local area.

\section{REFERENCES}

1. Case, M.C. (1994, Jan 26). Beyond the BA. The Chronicle of Higher Education p. A29-A31.

2. Clinton Unveils Plans for Higher Education Reform. (1993, June). NACUBO p. 6.

3. The College Board. (1993). Enrollment Planning Service, Logicat, Inc.

4. Copulsky, W. (1970). Practical Sales Forecasting. USA: American Management Association.

5. Deutsch, E. H. (1993, November 14). MBA Programs Right for Shrinking Pool of Students Interested in Business. The New York Times, p. 26.

6. Evangelauf, J.C. (1994, April 6). “A New 'Carnegie' Classification”. The Chronicle of Higher Education.

7. Falley P., Chair (1991 September 1). Report of the Strategic Planning Commission. Fairleigh Dickinson University.

8. "Good News/ Bad News". (1994, March) The CPA Letter p.2.

9. Hughes J.W., \& Hughes C.O. (1980). hU in the 1980s: A Snal2shot from the 1990 Census. NJSDC: NJDL.

10. Krohn, J. Personal Interview. 21 Feb 1994.

11. Lee, M. (1993, July). Global Competition: A Framework for Action in a Competitive World. NACUBO, p. 44 .

12. Lilien, L.L, \& Kottler, P. (1985). Marketing Decision Marking - A Model Building Approach . New York: Harper\& Row.

13. Lins, L. J. (1964). Methodology of Enrollment Projections for Colleges and Universities. AACRAO.

14. Mantella, P. (1993). Managing Enrollment During a Period of Transition. A Special Report for the Board of Trustees. Fairleigh Dickinson University.

15. McClave, J.T. (1991). Statistics for Business and Economics. San Francisco: Deflen Publishing Co.

16. Miller, R.B. (1985). Minitab. Belmont, California: PWS Publishers.

\section{EXHIBIT 1}

The 1994 Carnegie classification includes all colleges and universities in the United States that are degree-granting and accredited by an agency recognized by the U.S. Secretary of Education.

\section{Research Universities I}

These institutions offer a full range of baccalaureate programs are committed to graduate education through the doctorate, and give high priority to research. They award 50 or more doctoral degrees I each year. In addition, they receive annually $\$ 40$-million or more in federal support.

\section{Research Universities 11}

These institutions offer a full range of baccalaureate programs are committed to graduate education through the doctorate, and give high priority to research. They award 50 or more doctoral degrees' each year. In addition, they receive annually $\$ 40$-million between $\$ 15.5$-million and \$40-million in or more in federal support. ${ }^{2}$. 


\section{Doctoral Universities I}

In addition to offering a full range of baccalaureate programs. The mission of these institutions includes a commitment to graduate education through the doctorate. They award at least 40 doctoral degrees' annually in five or more disciplines. ${ }^{3}$

\section{Doctoral Universities H}

In addition to offering a full range of baccalaureate programs, the mission of these institutions includes a commitment to graduate education through the doctorate. They award annually at least 10 doctoral degrees-in three or more disciplinesk-or 20 or more doctoral degrees in one or more disciplines.

\section{Master's (Cokprehensrvz) Universities A" Colleges I}

These institutions offer a full range of baccalaureate programs and are committed to graduate education through the master's education through the master's degree. They award 40 or more master's degrees annually in one or more disciplines.

\section{Master's (Cokprehmswe) Umveitsrrm And Colleges $U$}

These institutions offer a full range of baccalaureate programs and are committed to graduate education through the master's degree. They award 20 or more master's degrees annually in one or more disciplines.

\section{Baccalaureate (Liberal Arts) Colleges}

These institutions are primarily undergraduate colleges with major emphasis on baccalaureate degree programs. They are selective in admissions and award 40 per cent or more of their baccalaureate degrees in liberal arts fields. ${ }^{4}$

\section{Baccalaureate (Liberal Arts) Colleges11}

These institutions are primarily undergraduate colleges with major emphasis on baccalaureate degree programs. They are less selective in admissions or they award less than $\mathbf{4 0}$ per cent of their baccalaureate degrees in liberal arts fields.

\section{Associate Of Arts Collwz5}

These institutions offer associate of arts certificate or degree programs and, with few exceptions, offer no baccalaueate degrees. ${ }^{5}$

\section{Professional Schools And Specialized Institutions}

These institutions offer degrees ranging from the bachelor's to the doctorate. At least 50 per cent of the degrees awarded by these in stitutions are in a specialized field. Specialized institutions include:

\section{Theological Seminaries, Bible Colleges And Other Institutions Offering Degrees In Religion}

This category includes institutions at which the primaty purpose is to offer religious instruction or train members of the clergy. 


\section{Medical Schools And Medical Centers}

These institutions award most of their professional degrees in medicine. In some instances, their programs include other degrees.

\section{NOTES}

